Case report

\title{
Invasive Hydatidiform Mole Showing Resistance to Single Etoposide Chemotherapy
}

\author{
Satoru Takeuchi \\ Department of Gynecology and Obstetrics, Kochi Health Sciences Center, Kochi, Japan
}

Key words: invasive hydatidiform mole, gestational trophoblastic disease, chemoresistance, blood flow

(J Rural Med 2008; 3(2): 41-44)

\section{Introduction}

Gestational trophoblastic disease (GTD) varies widely among various populations with figures as high as 1 in 120 pregnancies in some areas of Asia and South America compared with $0.6-1.1$ per 1000 in the United States ${ }^{1)}$. Approximately $92 \%$ of hydatidiform moles resolve spontaneously after evacuation, and the majority of the rest can be successfully treated with a minimum of toxicity ${ }^{2}$. However about $20 \%$ of cases become chemoresistant and require multi-agent chemotherapy such as MAC (MTX, ActD, Cyclophosphamide) or MEA (MTX, etoposide, Act-D). In general, GTD is hypervascular, and transvaginal ultrasonography is useful for detection of blood flow in the tumor during treatment to assess its activity.

\section{Case Presentation}

A 28-year-old woman with no gravida visited a clinic because of genital bleeding. The patient had normal menstrual periods until November 2005. She was diagnosed as having a hydatidiform mole and underwent a dilatation and curettage. Histological examination revealed a total hydatidiform mole. About one month after the curettage, she had massive genital bleeding with a $\mathrm{Hb}$ of $5.9 \mathrm{~g} / \mathrm{dL}$. Before the curettage, the urine hCG level was $306,695 \mathrm{mIU} / \mathrm{mL}$ (Table 1). On day 13 after the curettage, the serum $\beta$-human chorionic gonadotropin $(\beta$-hCG) level was $18 \mathrm{ng} / \mathrm{mL}$, and the level increased to $273 \mathrm{ng} / \mathrm{mL}$ at the time of massive bleeding. The patient was diagnosed as having an invasive hydatidiform mole by vaginal ultrasonography (US) and MRI. She was referred to our institution for treatment.

Correspondence to: Satoru Takeuchi

Kochi Health Sciences Center, Gynecology and Obstetrics, Ike 2125-1, Kochi City, Kochi 781-8555, Japan

E-mail: satoru_takeuchi@khsc.or.jp
When she visited our institution, her serum hCG level was $53,572 \mathrm{mIU} / \mathrm{mL}$. A vaginal US revealed a $2.8 \times 2.5 \times$ $4.3 \mathrm{~cm}$ tumor with a cystic component in the uterine body in which blood flow was identified (Fig. 1). In enhanced images $\mathrm{CT}$, an irregularly enhanced tumor was identified in the uterine body (Fig. 2). No tumor was identified in the abdomen or chest; a tumor was only identified in the uterine body. The patient was diagnosed as having a clinical invasive hydatidiform mole (WHO classification) in Stage $\mathrm{Ib}$ according to the FIGO Anatomical Staging. The disease was confined to the uterus. The patient's risk factor score was three (Modified WHO Prognostic Scoring System as Adapted by FIGO; Table 2). As the patient was in a low risk group (less than 7 points), a single etoposide treatment (100 $\mathrm{mg} / \mathrm{m}^{2}$ for 5 days iv with a three week interval) was adopted according to the General Rules for Clinical and Pathological Management of Trophoblastic Disease in Japan in 1995.

The level of serum hCG fell in good response until the 3rd course of single etoposide chemotherapy, but around the 4th course, it was elevated (Fig. 3). The patient was considered to have developed chemoresistance. A combination regimen of MAC was then performed instead of the single etoposide treatment. The serum hCG and $\beta$-hCG levels then began to decrease well and could not be detected after the first course of MAC therapy. The serum-hCG-CTP level could not be detected after the second course of MAC therapy. Another two courses of MAC were administered. After 4 courses of etoposide treatment, $2.7 \mathrm{~cm}$ tumor (max diameter) was identified by US and CT. After 2 courses of MAC therapy, the tumor could no longer be found and no blood flow was identified in the uterine muscle. Three months after the last chemotherapy, the basal body temperature was

Table 1. Transition of the hCG level

Before
curettage Day 13 Day 19 After 6 weeks At first visit

\begin{tabular}{|c|c|c|c|c|}
\hline $\begin{array}{l}\text { Urine hCG } \\
(\mathrm{mIU} / \mathrm{mL})\end{array} \quad 306,695$ & & 388 & 12,807 & 16,404 \\
\hline $\begin{array}{l}\text { Serum } \beta \text {-hCG } \\
(\mathrm{ng} / \mathrm{mL})\end{array}$ & 18 & & 273 & 267 \\
\hline
\end{tabular}



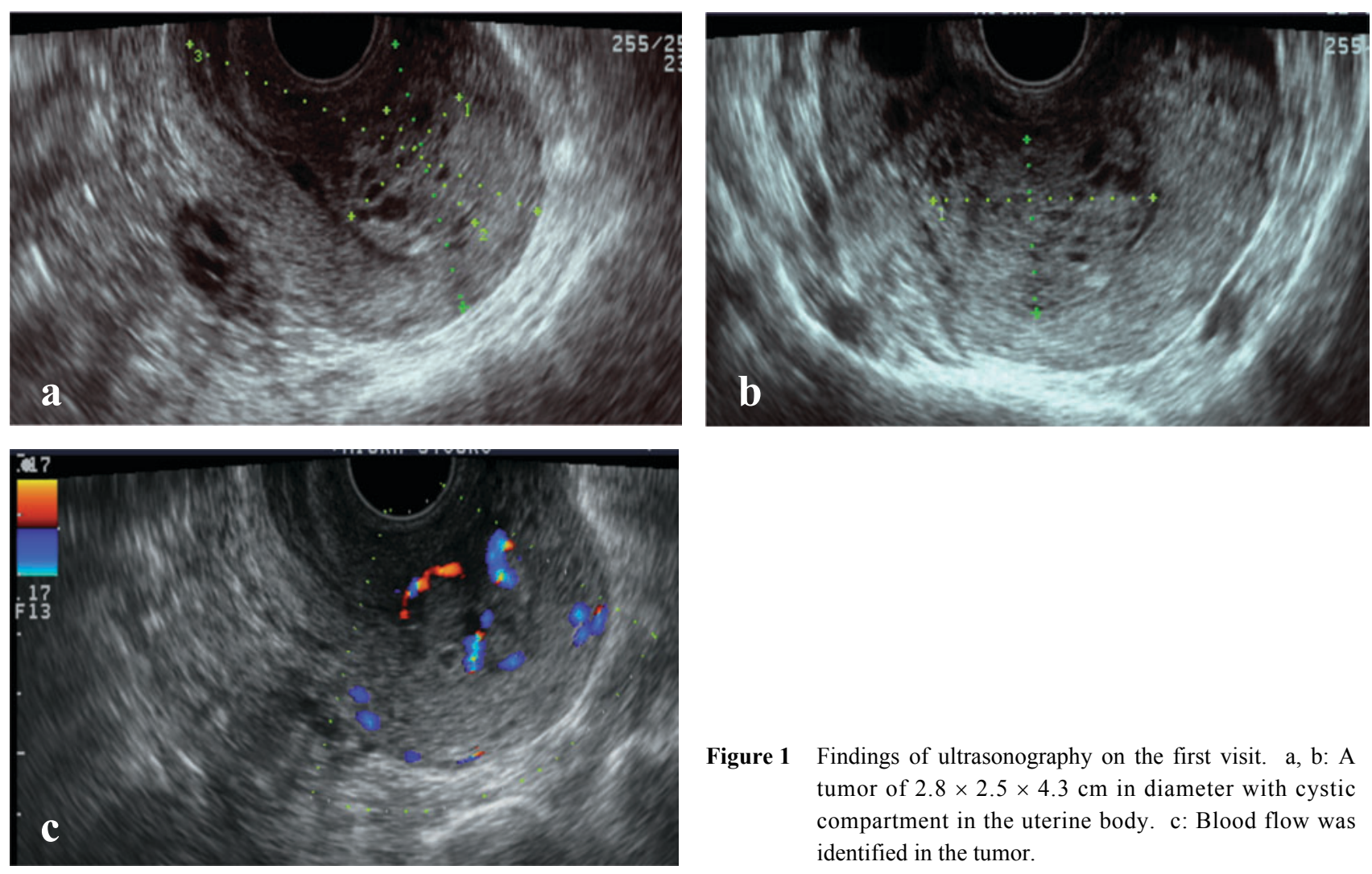

Figure 1 Findings of ultrasonography on the first visit. a, b: A tumor of $2.8 \times 2.5 \times 4.3 \mathrm{~cm}$ in diameter with cystic compartment in the uterine body. c: Blood flow was identified in the tumor.
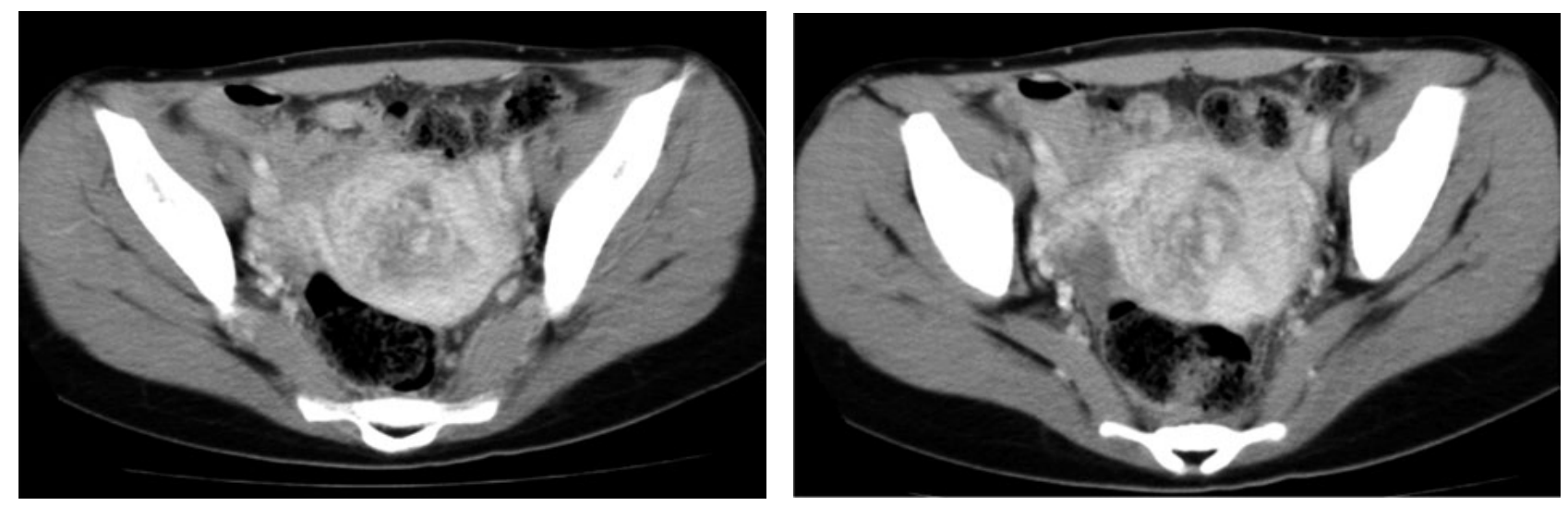

Figure 2 Findings of enhanced CT on the first visit. An irregularly enhanced tumor was identified in the uterine body.

biphasic. The patient became pregnant six months after the last MAC therapy and gave birth to a healthy newborn via a smooth vaginal birth.

\section{Discussion}

The total number of GTD cases has dropped steadily from $1938(1979-1981)$ to $483(1999-2001)^{3)}$. The exact reasons for this change are not apparent. Factors such as decreased parity and improved socioeconomic conditions in many countries may be responsible ${ }^{3)}$.

In normal pregnancy, the serum $\beta$-hCG level reaches a peak of $50,000-100,000 \mathrm{mIU} / \mathrm{mL}$ at about 12 weeks of gestation, decreases to $10,000-20,000 \mathrm{mIU} / \mathrm{mL}$ by 20 weeks and remains at that level until term ${ }^{4}$. Invading trophoblasts from hydatidiform moles and choriocarcinomas secrete higher amounts of hCG compared with trophoblasts in a normal pregnancy ${ }^{5}$. In GTD, higher levels of hCG may elicit stronger immunosuppression at the primary site, which allows malignant trophoblasts to escape from maternal immune system surveillance ${ }^{6,7)}$.

The current classification scheme of the World Health Organization is based on histologic characteristics and lists the hydatidiform mole (complete or partial), invasive mole, choriocarcinoma, placental site trophoblastic tumor, miscellaneous trophoblastic tumor and unclassified 
Table 2. Modified WHO prognostic scoring system adapted by FIGO

\begin{tabular}{llllll}
\hline Score & \multicolumn{1}{c}{0} & \multicolumn{1}{c}{2} & \multicolumn{1}{c}{4} \\
\hline Age & $<40$ & & $\geq 40$ & - & - \\
Antecedent pregnancy & Mole & Abortion & Term & - & $>12$ \\
Interval month from index pregnancy & $<4$ & $4-6$ & $7-12$ & $>10^{5}$ \\
Pretreatment serum hCG (iu/l) & $<10^{3}$ & $10^{3}-10^{4}$ & $10^{4}-10^{5}$ & - \\
Largest tumor size (cm; including uterus) & $<3$ & $3-4$ & 25 & Liver, Brain \\
Site of metastases & Lung & Spleen, Kidney & Gastro-intestinal & $>8$ \\
Number of metastases & - & $1-4$ & $5-8$ & Single drug & 2 or more drugs \\
Previous failed chemotherapy & - & - & &
\end{tabular}

Stage I: 3 (low risk group).

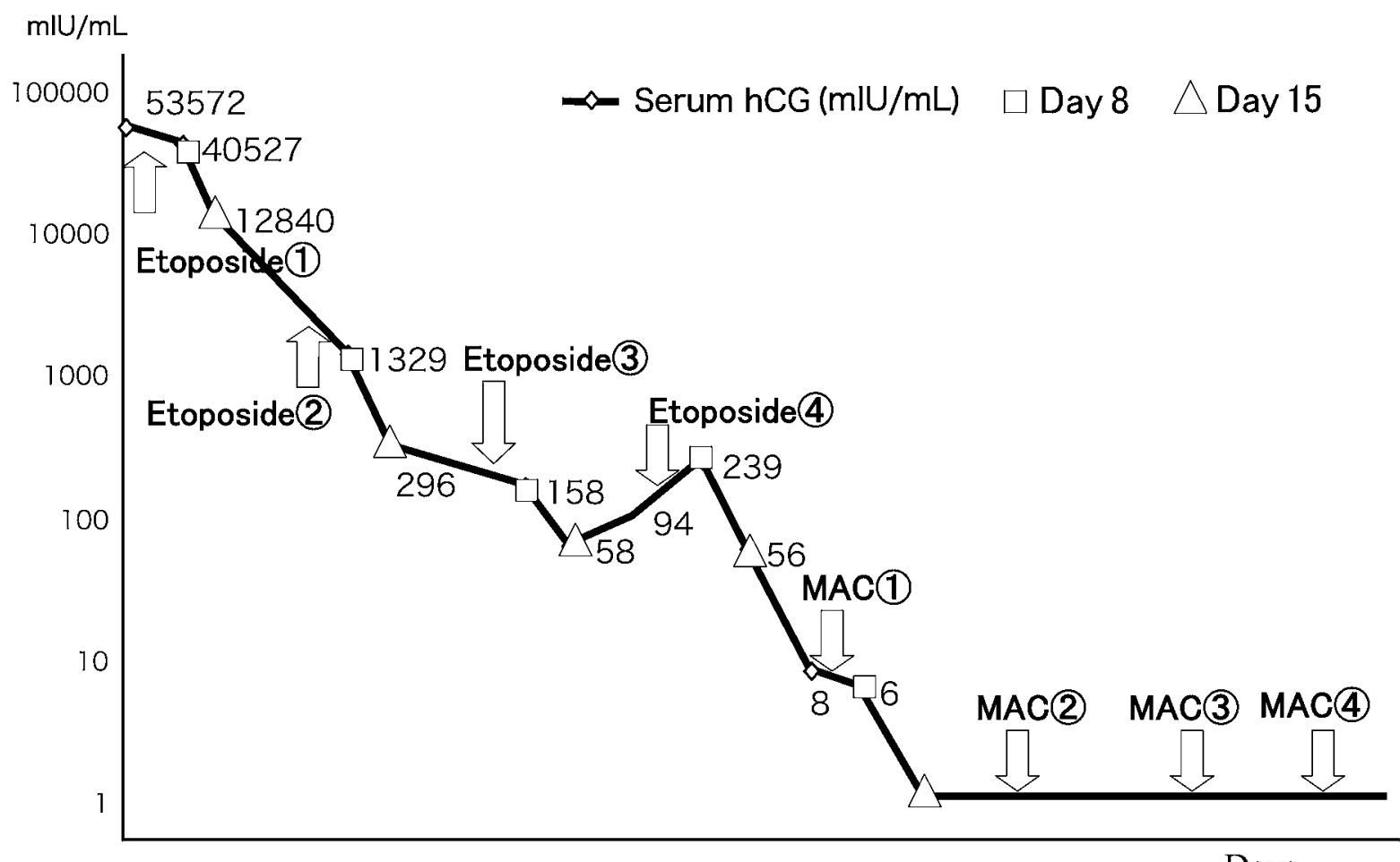

Figure 3 Transition of serum hCG level.

Days

trophoblastic lesions ${ }^{1,3,8-11)}$. Complete moles result from diandry (fertilization of an empty ovum), and partial moles result from diandric triploidy ${ }^{1)}$.

Persistent trophoblastic diseases develop in about 10-15 percent of patients after molar evacuation in Japan, and persistent trophoblastic diseases are classified into three groups: (1) post-molar persistent hCG; (2) invasive mole or metastatic moles; and (3) choriocarcinoma ${ }^{12}$. About $50 \%$ of choriocarcinoma originate from the normal pregnancies and the remaining $50 \%$ are transformed from invasive moles ${ }^{13}$.

GTD is rare in humans and is extremely responsive to chemotherapy even with metastatic forms ${ }^{14)}$. The remarkable curability of GTDs with chemotherapy might reflect the great blood flow of the tumor and the underlying immune response of the host (the mother) to paternal antigens expressed on the surface of the trophoblastic cells ${ }^{15)}$. Doppler study of the myometrium in invasive gestational trophoblastic disease has proven to be a useful diagnostic tool ${ }^{16)}$. A score of 6 or less indicates a low-risk disease treatable by single agent chemotherapy. A score of 7 or more indicates a high-risk disease requiring combination chemotherapy $^{3,8,17)}$. Most invasive moles have been accompanied by low-risk factors ${ }^{18)}$.

Chemotherapy is considered to be effective when the level of serum hCG after the chemotherapy decreases to one tenth of all observed pretreatment levels. A change of chemotherapy regimen is indicated in the following conditions: 1 . the serum hCG level rises by more than $10 \%$ for two to three consecutive values within a 1 - to 2 -week interval; 2 . the serum $\mathrm{hCG}$ level plateaus $( \pm 10 \%)$ for $2-3$ weeks; 3 . new metastases appear ${ }^{19)}$. The serum hCG level of the present case dropped to $58 \mathrm{mIU} / \mathrm{mL}$ after the third 
single etoposide chemotherapy. After that, it rose by more than $10 \%$ for two consecutive values within a 1 - to 2 -week interval. About $20 \%$ of cases become chemoresistant and require multi-agent chemotherapy. Chemotherapy with MAC is effective for many diseases when they show resistance to single agent chemotherapy ${ }^{19)}$.

After diagnosis of a molar pregnancy, follow-up is essential to detect patients who require chemotherapy ${ }^{20)}$. Follow-up mainly relies on serial measurements of serum hCG levels for at least half a year after evacuation ${ }^{21}$.

Patients treated for invasive hydatidiform mole seldom have problems involving post-treatment pregnancy or delivery ${ }^{22)}$. However, in cases of pregnancy or abortion after treatment with multi-cancer agents, heart malformations are seen in some newborns, and preservation of egg cells may pose a problem at the time of anti-cancer agent administration $^{22)}$. A previous study followed up patients who conceived within one year after multi-agent chemotherapy and conducted an analysis to determine an abnormal pregnancy result ${ }^{23}$ ). The wastage rate of the patients who conceived in the first half of the year was higher than that of the patients who concieved in the latter half of the year ${ }^{23)}$. Hydatidiform mole and post term choriocarcinoma have been reported in patients who conceived within 5 months after chemotherapy ${ }^{23)}$. In the present case, the patient became pregnant six months after the last MAC therapy and gave birth to a healthy newborn via a smooth vaginal birth.

\section{References}

1. World Health Organization Classification of Tumors International Agency for Research on Cancer (IARC). Pathology and genetics of tumors of the breast and female genital organs. Fattaneh A, Devilee TP, Eds. IARC Press, Lyon, 2003; 250-254.

2. Smith DB, O'Reilly SM, Newlands ES. Current approaches to diagnosis and treatment of gestational trophoblastic disease. Curr Opin Obstet Gynecol 1993; 5: 84-91.

3. $26^{\mathrm{TH}}$ Annual Report on the Results of Treatment in Gynecological Cancer. Guest Editor: Prof. S.Pecorelli. International Journal of Gynecology and Obstetrics 2006; 95(Suppl 1): S193-S203.

4. Dy Echo AV, Soriano-Estrella AS. Gestational trophoblastic tumor in pregnancy: a case report and review of the literature. Int J Gynecol Cancer 2006; 16: 875-881.

5. Perkins GL, Slater ED, Sanders GK, et al. Serum tumor markers. Am Fam Physician 2003; 68: 1075-1082.

6. Lin J, Lei ZM, Loujun S, et al. Increased expression of luteinizing hormone/human chorionic gonadotropin receptor gene in human endometrial carcinomas. J Clin Endocrinol Metab 1994; 79: 1483-1491.
7. Wang X, FU S, Freedman RS, et al. Immunobiology of gestational trophoblastic disease. Int J Gynecol Cancer 2006; 16: $1500-1515$.

8. Alici S, Eralp Y, Saip P, et al. Clinical characteristics of gestational trophoblastic disease at a single institute. Tohoku J Exp Med 2002; 197: 95-100.

9. Scully RE, Bonfiglio TA, Kurman RJ, et al. Histological typing of female genital tract tumors. $2^{\text {nd }}$ ed. Springer Verlag, New York, 1994.

10. Kohorn EI. The new FIGO 2000 staging and risk factor scoring system for gestational trophoblastic disease: description and critical assessment. Int J Gynecol Cancer 2001; 11: 7377.

11. Ngan HY, Bender H, Benedet JL, et al. Gesational trophoblastic neoplasia, FIGO 2000 staging and classification. FIGO Committee on Gynecologic Oncology. Int J Gynecol Obstet 2003; 83(Suppl 1): 175-177.

12. Sasaki S. Management of gestational trophoblastic disease in Japan —a review. Placenta 2003; 24(Suppl A): 28-32.

13. Cui JQ, Shi YF, Zhou HJ, et al. The changes of gene expression profiles in hydatidiform mole and choriocarcinoma with hyperplasia of trophoblasts. Int J Gynecol Cancer 2004; 14: 984-997.

14. Hoskins WJ, Peres CA,Young RC. Principles and Practice of Gynecologic Oncology, $3^{\text {rd }}$ edn. Lippencott, Williams and Wilkins, Philadelphia, 2000; 1117-1132.

15. Berkowitz RS, Goldstein DP, Anderson DJ. Recent advances in understanding the immunobiology of gestational trophoblastic disease-a review. Trophoblast Res 1987; 2: 123.

16. Oquz S, Seqin A, Avtan H, et al. Doppler study of myometrium in invasive gestational trophoblastic disease. Int $\mathbf{J}$ Gynecol Cancer. 2004; 14: 972-979.

17. Lurain JR. Treatment of gestational trophoblastic tumors. Curr Treat Options Oncol 2002; 3: 113-124.

18. Wang YX, Zhang X, Guan YL, et al. Assessment of staging and prognostic scoring system for malignant trophoblastic neoplasia. Zhonghus FU Chan Ke Za Zhi 2005; 40: 87-90.

19. El-Lamie IKL, EI Sayed HM, Badawie AG, et al. Evolution of treatment of high-risk metastatic gestational trophoblastic tumors: Ain Shams University experience. Int J Gynecol Cancer 2006; 16: 866-874.

20. Behtash $\mathrm{N}$, Ghaemmaghami $\mathrm{F}$, Honar $\mathrm{H}$, et al. Is normal $\beta$ hCG regression curve helpful in the diagnosis of persistent trophoblastic disease? Int J Gynecol Cancer 2004; 14: 980 983.

21. Cunningham FG, Gant NF, Leveno KJ, et al. Williams Obstetrics, 21st edn. McGraw-Hill, New York, 2001, 842.

22. Goto $\mathrm{S}$, Ino $\mathrm{K}$, Mitsui $\mathrm{T}$, et al. Choriocarcinoma treatment: goal and issues. Gan To Kagaku Roho 2005; 32: 1116-1112.

23. Zhu L, Yang X, Song H. Pregnancy of patients conceived within one year after chemotherapy for gestational trophoblastic tumor. Zhonghua Fu Chan Ke Za Zhi 1999; 34 : $618-620$. 